\title{
Assessment of Memory among Traumatic Brain Injury Patients during Follow-Up at a Tertiary Health Care Facility in Rural Setting
}

\begin{tabular}{|c|c|}
\hline Anamika Singh',® Raj Kumar ${ }^{2}$ Ahmad Ansari & Naresh Pal Singh ${ }^{3, \odot} \quad$ Amit Kant Singh ${ }^{1}$ \\
\hline $\begin{array}{l}\text { 1Department of Physiology, Uttar Pradesh University of Medical } \\
\text { Sciences (UPUMS), Saifai, Etawah, Uttar Pradesh, India } \\
\text { 2Department of Neurosurgery, Uttar Pradesh University of Medical } \\
\text { Sciences (UPUMS), Saifai, Etawah, Uttar Pradesh, India } \\
{ }^{3} \text { Department of Community Medicine, Uttar Pradesh University of } \\
\text { Medical Sciences (UPUMS), Saifai, Etawah, Uttar Pradesh, India }\end{array}$ & $\begin{array}{l}\text { Address for correspondence Raj Kumar, MS, MCh, PhD, } \\
\text { Department of Neurosurgery, Uttar Pradesh University of } \\
\text { Medical Sciences (UPUMS), Saifai, Etawah 206130, UP, India } \\
\text { (e-mail: rajkumar1959@gmail.com, vcoffice@upums.ac.in). }\end{array}$ \\
\hline
\end{tabular}

Indian J Neurosurg 2021;1:20-25.

\begin{abstract}
Keywords

- traumatic brain injury

- memory impairment

Background Head injury is an important public health problem nowadays. Traumatic brain injury (TBI) results from external force that leads to damage to brain tissue. Main causes of TBI are motor vehicle collisions and fall from height. One of the primary symptoms after TBI is impaired word retrieval. Therefore, this study was undertaken to assess memory impairment in TBI patients following treatment to asses a residual memory status to declare them apt for official works if improved enough.

Objectives The purpose of this study was to assess memory impairment in TBI patients to assess the residual memory status following treatment.

Materials and Methods The study was conducted in Outpatient Department (OPD) of Neurosurgery, Uttar Pradesh University of Medical Sciences, Saifai, Etawah, Uttar Pradesh. The TBI patients were assessed by predesigned memory assessment questionnaire during their follow-up following discharge from hospital.

Results A total of 65 patients with TBI were assessed, of which 21 (32.3\%) cases had frontal lobe injuries with 9 of 21 having memory loss ( $42.9 \%$ cases). The temporoparietal lobe was affected in $10(15.4 \%)$ cases out of which 5 developed memory loss, that is, $50 \%$ cases. The multiple lobes were involved in 24 (36.9\%) cases, out of which memory impairment occurred in 9 cases, that is, $37.5 \%$. Four of total five cases (80\%) of diffuse axonal injury had memory loss. Further, $16.9 \%(n=11)$ TBI patients were unable to perform digit span test (immediate memory test), $44.6 \%(n=29)$ cases could not perform three-word recall at 5 minutes (short-term memory test), and 15.4\% ( $n=10)$ cases could not perform (long-term memory test).

Conclusion The study showed that memory assessment is required in TBI patients for instituting proper rehabilitation measures and to allow them for sensitive memory-related work following discharge from hospital.
\end{abstract}

\section{Introduction}

Head injury is an important public health problem nowadays. In terms of number of cases and the number of deaths, head

DOI https://doi.org/ $10.1055 / \mathrm{s}-0040-1714165$ ISSN 2277-954X. injury is the leading factor. Moreover, severe head injury remained a challenge to neurosurgeons and basic neuroscientists, as the mortality and morbidity is very high in these cases. $^{1-7}$
(C) 2021. Neurological Surgeons' Society of India.

This is an open access article published by Thieme under the terms of the Creative Commons Attribution-NonDerivative-NonCommercial-License, permitting copying and reproduction so long as the original work is given appropriate credit. Contents may not be used for commercial purposes, or adapted, remixed, transformed or built upon. (https://creativecommons.org/licenses/by-nc-nd/4.0/)

Thieme Medical and Scientific Publishers Pvt. Ltd., A-12, 2nd Floor, Sector 2, Noida-201301 UP, India 
In traumatic brain injury (TBI), the external force results in varying degrees of damage to the brain tissue..$^{8-10}$ The common causes of TBI include road traffic accidents (RTA), violence, injuries at construction sites and sports, etc. ${ }^{11,12}$ In India, RTA is the commonest cause of TBI on account of increasing vehicles and inefficient road safety norms. Every minute there is one accident and every 4 minutes there is a death in India. An epidemiological study of head injuries in the population attending an emergency in the United Kingdom revealed head injury accounting for $3.4 \%$ of all attendances per year. Among them, $10.9 \%$ injuries were of moderate to severe grade. ${ }^{13}$ Considering the fact that motor vehicular accident is the leading cause of head injury worldwide, the World Health Organization dedicated the year 2004 to emphasize on this aspect by giving the theme "road safety" tips/teaching on the occasion of World Health Day. ${ }^{14}$

TBI results in damage to the brain due to external mechanical force such as rapid acceleration, impact, blast waves, or penetration by projectile objects. ${ }^{15}$ Brain injuries can be classified into mild, moderate, and severe categories according to Glasgow Coma Scale (GCS). In mild head injury, GCS score is 13 to 15 , moderate 9 to 12 , and in severe head injuries GCS score is less than or equal to $8 .{ }^{16}$ There are many features of head injury compromising higher mental functions among the survivors but one of the primary symptoms after TBI is impaired word retrieval. ${ }^{17}$ Word retrieval is the process of finding the correct terminology for picture, an object, orthographic representation, or conversation, in which a person converts the initial conception to a lexical version. ${ }^{18}$ TBIs result in death and disability, especially in children and young adults. ${ }^{19}$

There is no literature available related to memory assessment in TBI patients in rural areas of India as literacy has an impact on higher brain functions. Considering these aspects of trauma on brain functioning, this study was conducted among the TBI survivors attending the tertiary level health facility in rural setting to evaluate the various correlates (age, gender, and other socio-demographic profile) of TBI and its effect on memory functions of the victims following their treatment and discharge from hospital.

\section{Aim and Objectives}

1. To evaluate the memory status in mild and moderate brain injury study subjects following treatment and discharge.

2. To describe the socio-demographic profile of the TBI cases in rural settings of India.

\section{Materials and Methods}

This was a cross-sectional study conducted at Uttar Pradesh University of Medical Sciences, located at Saifai, in Etawah district of Uttar Pradesh, India. The study was conducted during the period of October 2018 to January 2019 after obtaining prior approval from the institutional ethical committee.

Cases who had been treated for TBI, attending the Neurosurgery Outpatient Department (OPD) during follow-up and who met the inclusion criteria, were included in this study. Most of these were admitted to the Indoor Patient Department in the Neurosurgery Department following TBI and were discharged after their appropriate case management. Those patients who had history of any neurodegenerative illness, alcohol or substance abuse, cognitive dysfunctions, and mental deterioration due to fulminant infection or neurological disorders, including patients with repeated trauma or any chronic illness, were excluded from the study. Patients who were unable to follow verbal as well as written commands and could not be assessed by neurocognitive battery of tests were also excluded from the study.

The subjects were enquired, and information was collected in the predesigned questionnaire that comprised of various socio-demographic variables. All the subjects were first examined by a faculty of Neurosurgery in the OPD and subsequently were referred for memory evaluation that was done by single Physiology faculty trained in testing neurological functions. The details of case history, mode of trauma, GCS score at admission, radiological findings, investigations performed, and treatment details like surgery or conservative management of cases were recorded from case files and discharge summaries. Memory status of each case was evaluated using tests for immediate, short-, and long-term memories. The memory functioning questionnaire was followed to assess this component adequately. Patients from 3 weeks to 6 months following treatment of TBI were evaluated for memory impairment.

We studied 65 patients of TBI. Patients were divided into two groups, namely mild and moderate TBI, based on GCS scores at the time of admission. Patients with severe GCS scores were not the part of our study.

Data thus collected were entered on Microsoft Excel worksheet and statistically analyzed using Statistical Package for the Social Sciences software version 21.

\section{Observations and Result}

- Table 1 depicts that majority of these cases of TBI were in the age group of 20 to 39 years (38.5\%) and 40 to 59 years (36.9\%). Among them, male patients were more (64.6\%) as compared with females. Majority of them were married (70.5\%), residing in joint families (61.5\%), and educated below intermediate (72.3\%). It also depicts that majority of the subjects were either unemployed or having some private job.

- Table 2 reveals that the proportion of memory loss was higher (80\%) among diffuse axonal injury (DAI), 50\% in temporoparietal lobe injury, while it was $37.5 \%$ and $32.3 \%$ in multiple lobe injury and frontal lobe injury, respectively. RTAs (75.4\%) were the commonest mode of injury. According to the GCS score at admission, it was observed that $75.4 \%$ cases had mild brain injury while $16.9 \%$ had moderate TBI and $7.7 \%$ had severe TBI. It was also observed that among all cases, $26.2 \%$ were operated for the brain injury while the remaining $73.8 \%$ were managed conservatively. Immediate, short-, and long-term memory status were assessed using various tests, which revealed that the TBI had more effect on the short-term memory with 
Table 1 Sociodemographic profile of the study subjects $(n=65)$

\begin{tabular}{|c|c|c|}
\hline Variable name & Frequency (n) & Percentage \\
\hline \multicolumn{3}{|l|}{ Age groups (in years) } \\
\hline$\leq 19$ & 10 & 15.4 \\
\hline $20-39$ & 25 & 38.5 \\
\hline $40-59$ & 24 & 36.9 \\
\hline $60-79$ & 6 & 9.2 \\
\hline \multicolumn{3}{|l|}{ Gender } \\
\hline Male & 42 & 64.6 \\
\hline Female & 23 & 35.4 \\
\hline \multicolumn{3}{|l|}{ Type of family } \\
\hline Nuclear & 25 & 38.5 \\
\hline Joint & 40 & 61.5 \\
\hline \multicolumn{3}{|l|}{ Educational status } \\
\hline Illiterate & 2 & 3.1 \\
\hline Below intermediate & 47 & 72.3 \\
\hline Intermediate & 2 & 3.1 \\
\hline Graduate and above & 14 & 21.5 \\
\hline \multicolumn{3}{|l|}{ Marital status } \\
\hline Unmarried & 18 & 27.7 \\
\hline Married & 46 & 70.8 \\
\hline Divorcee & 1 & 1.5 \\
\hline \multicolumn{3}{|l|}{ Occupation } \\
\hline Not working/housewife & 19 & 29.2 \\
\hline Student & 11 & 16.9 \\
\hline Private job & 19 & 29.2 \\
\hline Government job & 4 & 6.2 \\
\hline Businessman & 9 & 13.8 \\
\hline Others (farming, etc) & 3 & 4.6 \\
\hline
\end{tabular}

44.6\% cases being depicted in - Table 3 unable to recall three words at an interval of 5 minutes.Tests for analyzing memory status in patients using Frequency of Forgetting Scale revealed that there was more difficulty in recall of phone numbers (35.4\%) and personal dates (32.3\%). Approximately half of the cases (47.7\%) had (-Table 4) no difficulty in recognizing faces and name recalling.

- Table 5 shows that approximately half of the cases (44.6\%) were unable to recall past events occurred during the last 1 month following injury. Memory of remembering past events was very good for events that occurred years back.

\section{Discussion}

Motor vehicle collisions and fall from height disproportionately affects the young population (teenagers and young adults) and is more common in men than in women. ${ }^{20}$ The present study has also revealed that more than half of the TBI subjects were either teenagers or young adults and $64.6 \%$ of them were males.

It was observed that $75.4 \%$ of cases suffered from TBIs due to RTA, followed by fall from height (15.4\%). Various researchers in developed nations have reported fall from height (28\%), motor vehicular traffic accidents (20\%), and assault (11\%) as the leading causes of TBI. ${ }^{21-24}$ The highest incidence of motor vehicular traffic accidents has been reported in the 15 to 19 years age group, while fall was the leading etiology in the 0 to 4 and $>75$ years age groups..$^{25-29}$ Young age predilection can be explained on the basis that this being the productive period of life, most of these are bread earners of family at this age group. Aged drivers are most common victims for RTA as suggested by Owsley et $\mathrm{al}^{30}$ and Bilban. ${ }^{31}$ In puberty age group (32.3\%), there are more chances of accidents because of increase in testosterone level and catecholamine (epinephrine and norepinephrine), speeding and drink driving, and less use of seat belt while driving or sitting in the car. ${ }^{32,33}$ It was also observed that $70.8 \%$ of the TBI victims were married, which may be explained on the basis of increased responsibilities or problematic relationship leading to increase road risk behavior. Papez circuit, which is limbic associated structure, functions primarily in the cortical control of emotion and memory storage and contains centers that regulate aversion and gratification. Additional structures associated 
Table 2 Pattern of traumatic brain injury in the cases $(n=65)$

\begin{tabular}{|c|c|c|}
\hline Variable name & Frequency $(n)$ & Percentage \\
\hline \multicolumn{3}{|l|}{ Site of injury } \\
\hline Frontal lobe & 21 & 32.3 \\
\hline Tempo-parietal lobe & 10 & 15.4 \\
\hline Occipital lobe & 5 & 7.7 \\
\hline Multiple lobes involvement & 24 & 36.9 \\
\hline Diffuse axonal injury (DAI) & 5 & 7.7 \\
\hline \multicolumn{3}{|l|}{ Mode of injury } \\
\hline Road traffic accidents & 49 & 75.4 \\
\hline Fall from height & 10 & 15.4 \\
\hline Violence & 3 & 4.6 \\
\hline Others (animal attack, etc.) & 3 & 4.6 \\
\hline \multicolumn{3}{|l|}{ Glasgow outcome score at admission } \\
\hline Mild brain injury (13-15) & 49 & 75.4 \\
\hline Moderate brain injury (9-12) & 16 & 24.6 \\
\hline \multicolumn{3}{|l|}{ Glasgow outcome score at discharge } \\
\hline Mild brain injury (13-15) & 58 & 89.3 \\
\hline Moderate brain injury (9-12) & 7 & 10.7 \\
\hline \multicolumn{3}{|l|}{ Operation status } \\
\hline Done & 17 & 26.2 \\
\hline Not done (conservatively managed) & 48 & 73.8 \\
\hline
\end{tabular}

Table 3 Memory status of study subjects $(n=65)$ determined using various memory tests

\begin{tabular}{|l|l|l|l|}
\hline Memory test used & $\begin{array}{l}\text { Bad } \\
n(\%)\end{array}$ & $\begin{array}{l}\text { Fair } \\
n(\%)\end{array}$ & $\begin{array}{l}\text { Good } \\
n(\%)\end{array}$ \\
\hline Immediate memory tests & $11(16.9)$ & $40(61.6)$ & $14(21.5)$ \\
\hline Digit span test & $24(36.9)$ & $21(32.3)$ & $20(30.8)$ \\
\hline Repeating three words & $16(24.6)$ & $25(38.5)$ & $24(36.9)$ \\
\hline Naming months backward & $9(13.9)$ & $21(32.3)$ & $35(53.8)$ \\
\hline Interrupted counting & $29(44.6)$ & $16(24.6)$ & $20(30.8)$ \\
\hline Short-term memory tests & $4(6.2)$ & $6(9.2)$ & $55(84.6)$ \\
\hline Thee-word recall at 5 min & $10(15.4)$ & $21(32.3)$ \\
\hline How did you reach hospital & \multicolumn{2}{l|}{} \\
\hline Long-term memory tests & \multicolumn{2}{l|}{} \\
\hline Past event recall in past 25 y &
\end{tabular}

with the Papez circuit include the prefrontal cortex, septum, and amygdala. ${ }^{34}$ Damage to the mammillothalamic tract, ventral anterior nucleus, and ventral lateral nucleus at the floor of third ventricle during TBI can result in memory and language impairment. ${ }^{35}$ Amnesia can be a result of disconnection of mamillary bodies from the Papez circuit. ${ }^{36}$

Memory loss may affect a person in many ways. Forgetfulness can happen because of a busy lifestyle, depression, or as side effect of old age. However, memory impairment can also be a result of traumatic event such as a brain injury or as a side effect of Alzheimer's or dementia. An article by the National Institute of Neurological Disorders mentions that the most common side effect of TBI is memory loss. ${ }^{37}$ In the present study, out of total 65 patients with TBI, 21 patients had frontal lobe injury with 9 of them developing memory loss, that is, $42.9 \%$ cases. The temporoparietal lobe was affected in 10 cases out of which 5 developed memory loss, that is, $50 \%$ cases. The occipital lobe was affected in 5 cases but none developed memory loss. The multiple lobes were involved in 24 cases with memory loss observed 
Table 4 Memory status of study subjects $(n=65)$ determined using Frequency of Forgetting Scale for various tests

\begin{tabular}{|l|l|l|l|l|}
\hline S. no. & Test used & $\begin{array}{l}\text { Always } \\
\boldsymbol{n}(\%)\end{array}$ & $\begin{array}{l}\text { Sometimes } \\
\boldsymbol{n}(\%)\end{array}$ & $\begin{array}{l}\text { Never } \\
\boldsymbol{n}(\%)\end{array}$ \\
\hline 1 & Forgetting names & $8(12.3)$ & $27(41.5)$ & $30(46.2)$ \\
\hline 2 & Forgetting faces & $6(9.2)$ & $28(43.1)$ & $31(47.7)$ \\
\hline 3 & Forgetting appointments & $10(15.4)$ & $31(47.7)$ & $24(36.9)$ \\
\hline 4 & Forgetting things & $15(23.1)$ & $28(43.1)$ & $22(33.8)$ \\
\hline 5 & Forgetting direction to places & $15(23.1)$ & $26(40.0)$ & $24(36.9)$ \\
\hline 6 & Forgetting phone numbers & $23(35.4)$ & $19(29.2)$ & $23(35.4)$ \\
\hline 7 & Forgetting personal dates & $21(32.3)$ & $18(27.7)$ & $26(40.0)$ \\
\hline 8 & Forgetting what to buy from store & $18(27.7)$ & $27(41.5)$ & $20(30.8)$ \\
\hline 9 & Forgetting what you are doing & $17(26.2)$ & $27(41.5)$ & $21(32.3)$ \\
\hline 10 & Losing thoughts in conversation & $16(24.6)$ & $26(40.0)$ & $23(35.4)$ \\
\hline
\end{tabular}

Table 5 Memory status of study subjects $(n=65)$ determined using Remembering Past Event Scale for various tests

\begin{tabular}{|l|l|l|l|l|}
\hline S. No. & Test used & $\begin{array}{l}\text { Very bad } \\
\boldsymbol{n}(\%)\end{array}$ & $\begin{array}{l}\text { Fair } \\
\boldsymbol{n}(\%)\end{array}$ & $\begin{array}{l}\text { Very good } \\
\boldsymbol{n}(\%)\end{array}$ \\
\hline 1 & Events during last month & $29(44.6)$ & $19(29.2)$ & $17(26.2)$ \\
\hline 2 & Events between 6 mo and 1 y & $12(18.5)$ & $19(29.2)$ & $34(52.3)$ \\
\hline 3 & Events between 1 and 5 y & $4(6.2)$ & $16(24.6)$ & $45(69.2)$ \\
\hline 4 & Events between 6 and 10y & $2(3.1)$ & $12(18.5)$ & $51(78.4)$ \\
\hline
\end{tabular}

in 9 cases, that is, $37.5 \%$. DAI was observed in 5 cases; out of these, 4 developed memory loss, that is, $80 \%$ cases.

Memory loss may negatively impact an individual's ability to perform activities of daily living and function at job/office or as independently as they did prior to the impairment. It may also impact an individual's ability to work, remember work-related appointments, or remember coworkers' names. Most importantly, memory impairments may impact an individual's safety within the home or community. An individual suffering from memory loss may forget to turn off the stove after cooking, or may even get lost in the community and be unable to return home. ${ }^{37}$ Further, $16.9 \%(n=11)$ TBI patients were unable to perform digit span test (immediate memory test), $44.6 \%(n=29)$ cases could not perform threeword recall at 5 minutes (short-term memory test), and $15.4 \%(n=10)$ cases could not perform long-term memory test. Chung et al has also reported poorer performance on digital span test in cases with mild TBI affecting the superior longitudinal fasciculus, which is critical for attention and short-term memory. ${ }^{38}$

Present study also revealed that $32.3 \%$ victims had frontal lobe injury with memory loss and $75.4 \%$ of the cases had mild TBI. Kim et $\mathrm{al}^{39}$ had also suggested that in mild TBI patients, memory-facilitating functions of frontal lobe are comparatively preserved hence less chances of memory loss while memory functions are more affected in moderate TBI patients. Temporal lobe has frontal lobe projection that is necessary for various aspects of movement control, short-term memory, and affect. In our study, probably this is the reason for short-term memory loss in $50 \%$ of cases of TBI in rural setting. There was no memory impairment observed in TBI patients with injury to occipital lobe. This is because occipital lobe is not involved in memory storage and retrieval. Memory functions were significantly impaired in TBI with DAI (based on magnetic resonance imaging findings) as $80 \%$ of DAI patients were not able to perform various tests for memory assessment. DAI is the result of traumatic shearing forces that occur when the head is rapidly accelerated or decelerated, as may occur in car accidents, falls, and assaults. ${ }^{40}$

\section{Conclusion}

Memory play a major role in our life as it allows us to remember skills that we have learned or retrieve information that is stored in the brain, or even recall a previous moment that happened in the past. The study showed that memory loss was observed in $41.5 \%$ of TBI cases following treatment from 3 weeks to 6 months. Thus, periodic ongoing memory assessment of individuals with TBI is important as neurological recovery can keep occurring for several months or longer after certain types of severe brain injury. The ongoing assessment can also be used to examine an individual's response to rehabilitation and to improve his/her life after the injury and thus help in the better management of TBI cases. This can also assist in declaring these cases fit for memory-related works.

\section{Funding}

Self-financed research work.

\section{Conflict of Interest}

None declared. 


\section{References}

1 Kraus JF, Epidemiology. In: Elizabeth Frost, ed. NINS. Head Injury Clinical Management and Research. Geneva, Switzerland: AIREN (ISSN-1012-9871); 1990:113-24

2 Field JH, Epidemiology of head injury in England and Wales. London: Department of Health and Social Security, Her Majesty's Stationary Office; 1976

3 Jennett B, MacMillan R. Epidemiology of head injury. Br Med J (Clin Res Ed) 1981;282(6258):101-104

4 Selecki BR, Ring IT, Simpson DA, Vanderfield GK, Sewell MF. Trauma to the central and peripheral nervous systems: Part I: An overview of mortality, morbidity and costs; N.S.W. 1977. Aust N Z J Surg 1982 Feb;52(1):93-102

5 Klauber MR, Barrett-Connor E, Marshall LF, Bowers SA. The epidemiology of head injury: a prospective study of an entire community-San Diego County, California, 1978. Am J Epidemiol 1981;113(5):500-509

6 Edna TH, Cappelen J. Hospital admitted head injury. A prospective study in Trøndelag, Norway, 1979-80. Scand J Soc Med 1984;12(1):7-14

7 Kraus JF, Black MA, Hessol N, et al. The incidence of acute brain injury and serious impairment in a defined population. Am J Epidemiol 1984;119(2):186-201

8 Rogatzki MJ, Baker JS. Traumatic brain injury in sport with special focus on biomarkers of concussion injury. J Neurol Neurophysiol 2016;7:383

9 Huang SH, Zhou YH. Why molecular biomarkers of traumatic brain injury may never work: effects of glymphatic pathway dysfunction. J Trauma Treat 2016;5:309

10 Bruns J Jr, Hauser WA. The epidemiology of traumatic brain injury: a review. Epilepsia 2003;44(s10) :2-10

11 Kushner D. Mild traumatic brain injury: toward understanding manifestations and treatment. Arch Intern Med 1998;158(15):1617-1624

12 Faul M, Xu L, Wald MM, Coronado VG. Traumatic brain injury in the United States: Emergency department visits, hospitalizations, and deaths, 2002-2006. National Center for Injury Prevention and Control, Centers for Disease Control and Prevention (2010). Available at: http://www. cdc. gov/traumaticbraininjury/statistics. html, 2010 - ci.nii.ac.jp. Accessed October 22, 2019.

13 Yates PJ, Williams WH, Harris A, Round A, Jenkins R. An epidemiological study of head injuries in a UK population attending an emergency department. J Neurol Neurosurg Psychiatry 2006;77(5):699-701

14 Maas AI, Stocchetti N, Bullock R. Moderate and severe traumatic brain injury in adults. Lancet Neurol 2008;7(8):728-741

15 Langlois JA, Rutland-Brown W, Wald MM. The epidemiology and impact of traumatic brain injury: a brief overview. J Head Trauma Rehabil 2006;21(5):375-378

16 Saatman KE, Duhaime AC, Bullock R, Maas AI, Valadka A, Manley GT; Workshop Scientific Team and Advisory Panel Members. Classification of traumatic brain injury for targeted therapies. J Neurotrauma 2008;25(7):719-738

17 Ylvisaker M. Language and communication disorders following pediatric head injury. J Head Trauma Rehabil 1986;1:48-56

18 King KA, Hough MS, Walker MM, Rastatter M, Holbert D. Mild traumatic brain injury: effects on naming in word retrieval and discourse. Brain Inj 2006;20(7):725-732

19 Alves OL, Bullock R, Excitotoxic damage in traumatic brain injury. In: Clark RS, Kochanek P, eds. Brain Injury. Boston: Kluwer Academic Publishers; 20011

20 Cassidy JD, Carroll LJ, Peloso PM, et al; WHO Collaborating Centre Task Force on Mild Traumatic Brain Injury. Incidence, risk factors and prevention of mild traumatic brain injury: results of the WHO Collaborating Centre Task Force on Mild Traumatic Brain Injury. J Rehabil Med 2004;36(43(Suppl):28-60

21 Sankar G, Jaya K. The psychological problems and existentialist view of the great two Americans Ernest Hemingway and F Scot Fitzgerald: a glimpses. Arts Soc Sci J 2016;7:165

22 Archer T. Physical exercise and its impact on psychology. Clin Exp Psychol. 2016;2:e104

23 Sankar G. The cognitive insight and Jungian philosophy after the post-colonial era in American writer Ernest Hemingway. Arts Soc Sci J 2016;7:156

24 Moscote-Salazar LR, Satyarthee GD. Moving forward: the role of neuromonitoring in pediatric traumatic brain injury and targeted therapy. Clin Pediatr. 2016;1:103

25 Zink BJ. Traumatic brain injury outcome: concepts for emergency care. Ann Emerg Med 2001;37(3):318-332

26 Moscote-Salazar LR, Satyarthee GD. A sensible approach to pediatric mild traumatic brain injury: new roads and new vistas. Clin Pediatr. 2016;1:104

27 Atcherson SR, Mina Steele CL. Auditory processing deficits following sport-related or motor vehicle accident injuries. Brain Disord Ther 2016;5:204

28 Wiseman-Hakes C. A profile of sleep architecture and sleep disorders in adults with chronic traumatic brain injury. J Sleep Disord Ther 2015;5:224

29 Olivera A. Combination treatment of natural compounds and integrative therapies for mild traumatic brain injury. Brain Disord Ther 2015;4:198

30 Owsley C, Stalvey BT, Phillips JM. The efficacy of an educational intervention in promoting self-regulation among highrisk older drivers. Accid Anal Prev 2003;35(3):393-400

31 Bilban M. Road traffic accidents caused by elderly drivers. Coll Antropol 1997;21(2):573-583

32 Reported Road Casualties Great Britain. Department for Transport,AnnualReport:2014.Availableat:https://assets.publishing.service.gov.uk/government/uploads/system/uploads/ attachment_data/file/463350/rrcgb2014-00.pdf Accessed December 20, 2019.

33 National Highway Traffic Safety Administration. Traffic Safety Facts 2016: Young Drivers. Washington, DC: U.S. Department of Transportation; 2018. Available at: https://crashstats. nhtsa.dot.gov/Api/Public/ViewPublication/812498External. Accessed July 24, 2018

34 Bigbee J, Papez circuit. In: Kreutzer JS, DeLuca J, Caplan B. eds. Encyclopedia of Clinical Neuropsychology. New York: Springer; 2011

35 Nishio Y, Hashimoto M, Ishii K, Mori E. Neuroanatomy of a neurobehavioral disturbance in the left anterior thalamic infarction. J Neurol Neurosurg Psychiatry 2011;82(11):1195-1200

36 Beglinger LJ, Haut MW, Parsons MW. The role of the mammillary bodies in memory: a case of amnesia following bilateral resection. Eur J Psychiatry 2006;20(2):88-95

37 Franklin Institute. The human brain. Resources for Science Learning Available at: www.fi.edu/learn/brain/stress.html. Accessed December 18, 2019

38 Chung S, Wang X, Fieremans E, et al. Altered relationship between working memory and brain microstructure after mild traumatic brain injury. AJNR Am J Neuroradiol 2019;40(9):1438-1444

39 Kim JS, Kim OL, Seo WS, Koo BH, Joo Y, Bai DS. Memory dysfunctions after mild and moderate traumatic brain injury: comparison between patients with and without frontal lobe injury. J Korean Neurosurg Soc 2009;46(5):459-467

40 Gennarelli TA. Mechanisms of brain injury. J Emerg Med 1993;11(1, Suppl 1):5-11 